\title{
EL CONTROL ORGANIZACIONAL
}

Las organizaciones contemporáneas se caracterizan por la flexibilidad, adaptación y aprendizaje continuo, por lo que el centro de atención del control se ha trasladado de los problemas de control de las personas y tareas, al control de la organización. En consonancia con los cambios que van sucediendo, las investigaciones deben orientarse hacia una perspectiva más amplia. Así, se observa que el conjunto de aspectos que se deben incluir bajo el control organizacional está evolucionando con estudios que tienen en cuenta el desempeño, los procesos de control y la cultura organizativa (Lere y Portz, 2005).

Siguiendo el enfoque planteado por Flamholtz et al. (1985), los trabajos sobre control organizacional se agrupaban bajo tres perspectivas que han dominado los estudios sobre las organizaciones: la sociológica, la administrativa y la psicológica. Investigaciones posteriores, como la de Simons y Merchant (1986) se refieren a los distintos enfoques bajo los cuales se ha estudiado el control en las organizaciones, recogiendo básicamente seis áreas: los principios de la administración, la perspectiva cibernética, la teoría de la agencia, la perspectiva psicológica, el enfoque contingente y el estudio de casos.

Estas posiciones reconocen la importancia del individuo y su comportamiento en relación con el grupo u organización a la que pertenece. La mayor parte de la literatura ha centrado la atención en la perspectiva administrativa, mientras que ha sido menos estudiado el control desde un enfoque sociológico que observe el 
comportamiento en la organización o en los grandes grupos dentro de esta y el control desde el individuo como ser psicológico centrado en la mente, dirigido a metas, dotado de procesos que permiten guiar conductas creativas en un contexto cambiante donde se ofrecen diversas situaciones en las que participan.

En tal sentido la línea de investigación en control organizacional de la Facultad de Contaduría Pública de la Universidad Externado de Colombia registra la necesidad de estudiar el sistema de gestión, la dirección por objetivos bajo un enfoque estratégico que reconoce el dominio de las habilidades gerenciales y los métodos y herramientas para el control de procesos en las organizaciones. Aprovechamos este espacio para invitar a los investigadores que deciden formar parte de nuestra revista a enviar contribuciones empíricas que establezcan discusiones al respecto.

Por otro lado, ponemos a su disposición el número 26 de la revista Apuntes Contables, el cual está integrado por artículos que reconocen la importancia del emprendimiento, la auditoria, el turismo sostenible, la eficiencia en mercados emergentes, normas internacionales de información financiera y preferencias de financiación.

¡Esperamos contribuir a su quehacer investigativo!

Marisleidy Alba Cabañas PhD

Editora

\section{REFERENCIAS BIBLIOGRÁFICAS}

Flamholtz, E. G., Das, T. K. y Tsui, A. S. (1985). Toward an integrative framework of organizational control. Accounting, organizations and society, 10(1), 35-50.

Lere, J. C. y Portz, K. (2005). Management control systems in a global economy. The CPA Journal, 75(9), 62.

Otley, D., Broadbent, J. y Berry, A. (1995). Research in management control: an overview of its development. British Journal of management, 6, S31-S44.

Simons, R. y Merchant, K. A. (1986). Research and control in complex organizations: an overview. 